\title{
ALTERNÂNCIA DE ESTILO EM ENTREVISTAS SOCIOLINGUÍSTICAS: UMA APLICAÇÃO DOS CRITÉRIOS DA ÁRVORE DE DEEISÃO LABOVIANA
}

\author{
Elisa BATTISTI1 \\ Bruna Silva dos SANTOS2 \\ Rodrigo Lerner GUTTERRES 3 \\ Thomaz Torres TEIXEIRA ${ }^{4}$ \\ Victória Goulart CUNHA ${ }^{5}$
}

\section{DOI: http://dx.doi.org/10.21165/gel.v18i3.3152}

Resumo: Este artigo discute os critérios de identificação de estilos contextuais previstos pela Árvore de Decisão (LABOV, 2001) e aplica-os a transcrições de entrevistas sociolinguísticas. Retomam-se os critérios da Árvore de Decisão, um dispositivo metodológico usado para investigar variação linguística intrafalante e alternância estilística em entrevistas sociolinguísticas, e revisam-se propostas de outros estudiosos acerca do dispositivo (BAUGH, 2001; SCHILLING-ESTES, 2004, 2007; GÖRSKI; VALLE, 2014; VALLE; GÖRSKI, 2014; FREITAG, 2014; DANTAS; GIBBON, 2014). O objetivo do artigo é demonstrar os desafios de identificar estilos contextuais e efetuar a anotação da trilha Estilo em transcrições de entrevistas do acervo LínguaPOA (2015-2019). Mostra-se que algumas limitações dos critérios da Árvore de Decisão, decorrentes da concepção laboviana de alternância estilística como resultado de graus distintos de atenção prestada à fala, podem ser superados considerando-se elementos da interação entre informante e pesquisador na entrevista sociolinguística.

Palavra-chave: Árvore de Decisão. Alternância de estilo. Entrevistas sociolinguísticas. Variação linguística intrafalante. LínguaPOA.

\footnotetext{
1 Universidade Federal do Rio Grande do Sul (UFRGS), Porto Alegre, Rio Grande do Sul, Brasil; battisti.elisa@gmail.com; https://orcid.org/0000-0002-6701-4218

2 Universidade Federal do Rio Grande do Sul (UFRGS), Porto Alegre, Rio Grande do Sul, Brasil; brunacortezi.bc@gmail.com; https://orcid.org/0000-0002-5719-6871

3 Universidade Federal do Rio Grande do Sul (UFRGS), Porto Alegre, Rio Grande do Sul, Brasil; digolerner2@gmail.com,http://orcid.org/0000-0002-5421-486X

4 Universidade Federal do Rio Grande do Sul (UFRGS), Porto Alegre, Rio Grande do Sul, Brasil; thomaztt1@gmail.com; http://orcid.org/0000-0002-8141-5608

5 Universidade Federal do Rio Grande do Sul (UFRGS), Porto Alegre, Rio Grande do Sul, Brasil; victoriagcunha@gmail.com; https://orcid.org/0000-0003-0335-646X
} 
- Alternância de estilo em entrevistas sociolinguísticas: uma aplicação dos critérios da Árvore de Decisão laboviana

\section{STYLE-SHIFTING IN SOCIOLINGUISTIC INTERVIEWS: AN APPLICATION OF THE CRITERIA OF THE LABOVIAN DECISION TREE}

Abstract: This paper discusses the criteria for identifying contextual styles provided by the Decision Tree (LABOV, 2001) and applies them to transcripts of sociolinguistic interviews. The Decision Tree, a methodological device used to investigate intra-speaker linguistic variation and stylistic alternation in sociolinguistic interviews, is approached in the paper along with proposals from other scholars about the device (BAUGH, 2001; SCHILLINGESTES, 2004, 2007; GÖRSKI; VALLE, 2014; VALLE; GÖRSKI, 2014; FREITAG, 2014; DANTAS; GIBBON, 2014). The objective of the paper is to demonstrate the challenges of applying the criteria to the annotation of the Style tier in transcripts of interviews from the LinguaPOA corpus (2015-2019). The paper shows that some limitations of the Decision Tree criteria, arising from the Labovian conception of style-shifting as the result of different degrees of attention paid to speech, can be overcome by considering elements of the interaction between informant and researcher in the sociolinguistic interview.

Keywords: Decision Tree. Style-shifting. Sociolinguistic interviews. Intra-speaker variation. LinguaPOA.

\section{Introdução}

Este artigo trata do desafio de identificar estilos contextuais de fala em entrevistas sociolinguísticas. Tais entrevistas são o procedimento clássico de coleta de dados da Sociolinguística Variacionista (LABOV, 2008) ${ }^{6}$. Embora as entrevistas sociolinguísticas labovianas contemplem fala pública - gravada, enunciada como resposta a perguntas feitas por um pesquisador desconhecido - e, por essa razão, produzam fala distinta da vernacular ou casual, organizam-se em subseções cujas perguntas buscam eliciar, do informante, uma gama de estilos de fala diferenciados, sendo que ao menos um deles

6 A Sociolinguística Variacionista estuda a variação e a mudança linguística. Com base em Weinreich, Labov e Herzog (2006), Labov (2008), essa linha de investigação analisa a correlação de variáveis observadas na fala - como, em português, a alternância entre nós::a gente na expressão de primeira pessoal de plural, ou entre forma ditongada e não ditongada (vocêis::vocês) de vogais tônicas em sílabas fechadas por /s/ - com condicionadores linguísticos e sociais. Os condicionadores linguísticos dizem respeito aos níveis da gramática - fonologia, morfologia, sintaxe - e os condicionadores sociais, à organização da comunidade de fala nos diferentes estratos que a compõem: idade, escolaridade, sexo/gênero, entre outras macrocategorias. 
fica o mais próximo possível da fala casual ou não monitorada ${ }^{7}$. Tal organização baseia-se na ideia de que a alternância de estilos ao longo da entrevista e a consequente produção de variação linguística intrafalante são condicionadas, basicamente, pelo grau de atenção que o informante presta às formas da fala, não a seu conteúdo: quanto mais monitorada a fala, maior a ocorrência de variantes conformes à linguagem padrão ${ }^{8}$; quanto menos monitorada, maior a ocorrência de variantes vernaculares, eventualmente distantes da linguagem padrão.

Esse arranjo dos contextos de alternância de estilos de fala em um continuum unidimensional, o "da atenção prestada à fala, com a fala casual numa extremidade do continuum e os pares mínimos na outra" (LABOV, 2008, p. 126), possibilita, como Labov desejava, segmentar trechos da entrevista sociolinguística e quantificar a atenção prestada à fala. No entanto, não esclarece integralmente as motivações da alternância estilística, tanto nas entrevistas sociolinguísticas quanto nos usos da linguagem em geral. Isso se deve, segundo Milroy e Gordon (2003), ao fato de a atenção prestada à fala ser apenas uma das dimensões em que se encontram motivações para a alternância de estilos de fala. É uma das reações possíveis dos falantes à situação social. Outra reação à situação social tem a ver, segundo Bell (2001), com as pessoas com quem se fala, isto é, com a audiência: as pessoas alternam estilos de fala como resposta às expectativas de seus interlocutores. Além disso, a alternância estilística pode resultar, segundo Milroy e Gordon (2003), do empenho dos falantes para, na fala situada, construir personae e projetar posicionamentos via indexação de significados sociais, como mostram os estudos de Eckert (2000) e Coupland (2007). Ou seja, a alternância de estilos de fala encontra motivações em diferentes dimensões dos usos da linguagem.

Vale destacar, também, que, nos trechos de fala mais monitorada na entrevista, o informante nem sempre fará uso de variantes conformes à linguagem padrão, assim como,

7 Em The social stratification of English in New York City (1966), estudo pioneiro de Labov sobre variação fonológica no inglês de nova-iorquinos, conforme o relatado nos capítulos 3 e 4 de Labov (2008), o autor constatou variação sistemática em estilos e contextos diferentes para as cinco variáveis linguísticas que ele investigou. Labov distinguiu cinco contextos possíveis de alternância estilística nas entrevistas: o contexto A, de fala casual ou não monitorada: fala com o entrevistador antes da entrevista propriamente dita, fala com terceiros, parlendas e rimas infantis, fala que não responde diretamente às perguntas do entrevistador. Os demais são de fala cuidada ou monitorada: o contexto B, de fala na situação de entrevista, o contexto C, de leitura em voz alta de textos, o contexto D, de leitura em voz alta de listas de palavras e de pares mínimos distintivos. O estudo de Labov em Nova lorque confirmou o incremento na proporção de uso de variantes mais prestigiadas, conformes à linguagem padrão - por exemplo a realização de $/ \mathrm{r}$ / em coda silábica na variável $(r)$ - com o aumento da atenção prestada à fala.

8 Denominamos linguagem padrão os usos linguísticos que mais se aproximam da norma-padrão, entendida, conforme Preti (2000), Bagno, (2003, 2007), Faraco (2008), como um modelo de língua, um conjunto de regras que orienta usos de linguagem, mas que não corresponde a manifestações linguísticas de fato observadas, sejam elas faladas ou escritas. 
- Alternância de estilo em entrevistas sociolinguísticas: uma aplicação dos critérios da Árvore de Decisão laboviana

ao falar casualmente, nem sempre usará apenas variantes não-padrão. Por exemplo, Schilling-Estes (2007) observa, na entrevista sociolinguística de Felícia, uma informante afro-americana de uma comunidade rural da Carolina do Norte, que, nos contextos de fala casual Narrativa e Tangente ${ }^{9}$, não há apenas um padrão de fala. Felícia articula variáveis peculiares à fala vernacular em inglês negro americano com variáveis conformes ao inglês padrão, a depender de aspectos relevantes ao desenrolar da interação na entrevista, como o tópico sobre que se fala, o controle conversacional, ou até mesmo a incorporação da fala de outras pessoas em trechos de fala reportada.

O presente artigo segue Schilling-Estes (2007) e considera que as entrevistas sociolinguísticas são uma fonte valiosa de estilos de fala, bem como de informações sobre as motivações para sua alternância. Como propõe a autora, assume-se uma concepção multidimensional da alternância estilística, admitindo-se que há sempre algum grau de performatividade em todos os estilos de fala e reconhecendo-se que, especialmente nas entrevistas sociolinguísticas, os estilos de fala possam ser autoconscientes (do inglês selfconscious styles). Acreditamos que o estudo sistemático da alternância estilística tenha papel fundamental no empreendimento sociolinguístico, por explorar a ligação entre indivíduo e comunidade e por lançar luz à avaliação das identidades sociais dos falantes e dos significados sociais das variáveis, o que pode fornecer respostas ao problema da implementação da variação e mudança linguística (WEINREICH; LABOV; HERZOG, 2006).

O artigo relata e discute a aplicação dos critérios da Árvore de Decisão laboviana à identificação de contextos de alternância estilística em entrevistas sociolinguísticas do LínguaPOA (2015-2019) ${ }^{10}$. Esses critérios são o ponto de partida para o registro, na trilha Estilo das transcrições em ELAN"1 das entrevistas, dos trechos de fala nos diferentes tipos

\footnotetext{
9 Narrativa e Tangente são dois dos oitos contextos em que se pode verificar alternância de estilo (entre fala casual e fala cuidada) em entrevistas sociolinguísticas conforme a Árvore de Decisão de Labov (2001), de que se tratará na seção a seguir.

10 O LínguaPOA é um banco de dados de fala. Contém uma amostra da variedade de português brasileiro de Porto Alegre, registrada nos áudios de 103 entrevistas sociolinguísticas de informantes porto-alegrenses, mais as transcrições dessas entrevistas e os documentos referentes a cada informante - Termo de Consentimento Livre e Esclarecido, Ficha de Entrevista, Questionário Econômico. Resultou do projeto de pesquisa Variação fonético-fonológica e classe social na comunidade de fala de Porto Alegre, do (PPGLetras-UFRGS/CNPq) e aprovado pelo Comitê de Ética em Pesquisa da UFRGS, parecer nº 991.732 de 19/03/2015. As 103 entrevistas são estratificadas em (a) quatro zonas: Centro (Central), Norte, Sul, Leste; (b) dois bairros por zona: renda alta e renda baixa (por renda domiciliar média mensal em salários mínimos); (c) três grupos etários: 20-39 anos, 40-59 anos, 60 ou mais anos; (d) três níveis de escolaridade: fundamental, médio, superior; (e) dois gêneros: masculino e feminino. As 103 entrevistas atendem a todos os critérios de estratificação nos níveis médio e superior de escolaridade, mas não no fundamental.
}

11 ELAN é um programa computacional (disponível em https://archive.mpi.nl/tla/elan, acesso em 07/07/2021) para anotação de arquivos de áudio e vídeo. A anotação é feita em trilhas com diferentes funções. Além das trilhas sugeridas por Oushiro (2014) para pesquisas sociolinguísticas - uma trilha para cada participante da gravação, uma trilha para dados contextuais e uma trilha para identificar partes do roteiro de entrevista as transcrições das entrevistas sociolinguísticas do LínguaPOA (2015-2019) contam com a trilha Estilo, para registro dos diferentes estilos contextuais de fala. 
de estilos contextuais. O objetivo do artigo é o de oferecer a outros pesquisadores, especialmente àqueles envolvidos na constituição e manutenção de bancos de dados de fala com entrevistas sociolinguísticas, subsídios para incluir, na transcrição das entrevistas, informações sobre estilos contextuais. A anotação do corpus para estilos contextuais permite o tratamento de grandes quantidades de texto rapidamente (BERBER SARDINHA, 2004) e atende à necessidade apontada por autores como Miller e Biber (2015) de aumentar a representatividade interna do corpus, dando-se atenção a aspectos que viabilizem descrições confiáveis da variação linguística.

O artigo parte de uma breve apresentação da Árvore de Decisão laboviana e de uma revisão de literatura a respeito da Árvore, com sugestões de desenvolvimentos desse dispositivo. Em seguida, discute-se a complexidade de usar os critérios da Árvore na identificação de contextos de alternância estilística nas entrevistas do LínguaPOA, não só em função da unidimensionalidade da perspectiva estilística laboviana, mas também em razão das diferenças na estruturação das entrevistas desse acervo em relação à organização das entrevistas utilizadas por Labov e colaboradores ao proporem a Árvore. Por fim, apresentamos diretrizes para a utilização desses critérios, ilustrando-as com excertos de entrevistas do LínguaPOA.

\section{A Árvore de Decisão laboviana}

Após o estudo pioneiro dos estilos contextuais (ver nota 2), Labov, juntamente com seus alunos da Universidade da Pensilvânia, refinou as categorias contextuais com base na análise de entrevistas de mais de 180 informantes da Filadélfia. Chegou a um conjunto de critérios para identificar estilos de fala em entrevistas sociolinguísticas, reunidos em um dispositivo que ele denomina Árvore de Decisão (LABOV, 2001).

A Árvore de Decisão (Figura 1) organiza-se nos eixos da fala casual e da fala cuidada e os critérios são neles dispostos conforme uma escala de objetividade. Visa à segmentação e análise da fala na entrevista sociolinguística, para identificar especialmente os trechos de fala espontânea ou não monitorada produzidos pelo informante. Para isso, a Árvore conta com quatro nós no eixo de fala monitorada12 (Careful speech) - Resposta, Língua, Soapbox e Residual - e quatro nós no eixo de fala espontânea ou casual (Casual speech) Narrativa, Grupo, Infância e Tangente. Os quatro critérios da parte de cima da árvore são mais objetivos, "de modo que as primeiras quatro decisões possam ser feitas com o mais alto grau de confiabilidade." (LABOV, 2001, p. 89, tradução nossa'³).

12 Optamos por usar o termo "monitorada" no lugar de "cuidada" em função de a Árvore de Decisão reunir critérios referentes à atenção prestada à fala, isto é, ao seu monitoramento.

13 No original: "so that the first four decisions can be made with the highest degree of reliability.". 
- Alternância de estilo em entrevistas sociolinguísticas: uma aplicação dos critérios da Árvore de Decisão laboviana

Figura 1. Árvore de Decisão

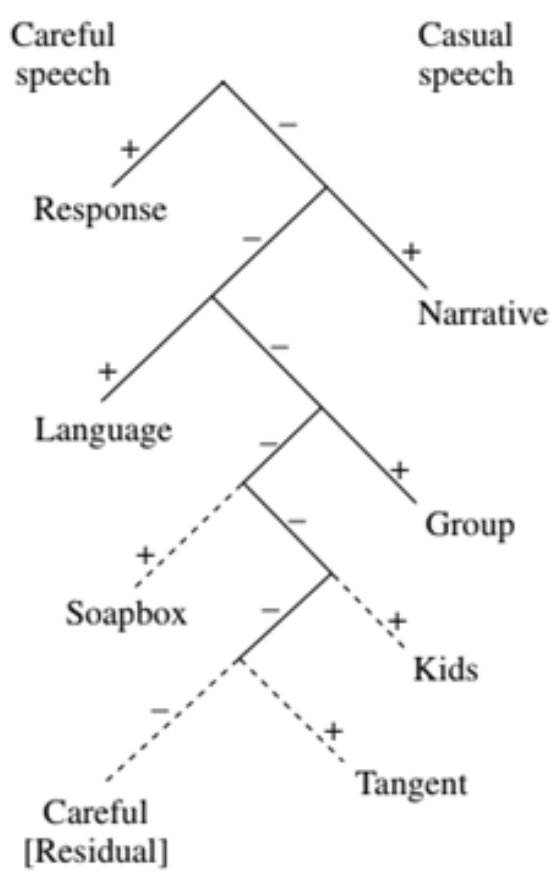

Fonte: Labov (2001, p. 94).

O nó Resposta, o primeiro da Árvore de Decisão, situa-se à sua esquerda, onde estão os estilos de fala monitorada. Nas entrevistas, Resposta é o trecho de fala do informante imediatamente seguinte à pergunta do entrevistador. Pode ser o primeiro trecho de outros nós contextuais: Narrativa, Tangente etc., o que é um primeiro desafio à identificação de estilos contextuais. Outro desafio é o fato de que, muitas vezes, o entrevistador coopera com o informante, produzindo feedbacks ou ecos ao longo da entrevista, sequências voltadas a orientar o falante e monitorá-lo quanto à recepção, conforme Marcuschi (2003), o que parece não ter efeito sobre o estilo de fala do informante. De acordo com Valle e Görski (2014), a diferenciação entre feedbacks (Nossa, como assim?) e ecos (D: Com quem tu trabalha? S: Com quem eu trabalho?), de um lado, e respostas de outro, é bastante difícil, especialmente no caso de repetições por parte do informante da última fala do entrevistador: "a parte repetida deve ser considerada resposta ou deve ser entendida comofeedback ou eco? A entonação interfere nessa decisão - se for semelhante, é eco; se for diferente, é resposta?" (VALLE; GÖRSKI, 2014, p. 108).

Outro desafio na identificação de estilos contextuais em relação à Resposta são comentários do entrevistador em meio à fala do informante, sejam eles uma pergunta sobre o assunto, sejam apenas comentários avaliativos. O problema é: nesses casos, deve- 
se segmentar o trecho de fala do informante imediatamente seguinte à fala do entrevistador como Resposta, para então voltar à segmentação anterior (Narrativa, Tangente, Residual etc.)?

A Narrativa, segundo nó da árvore, situado à sua direita, no eixo de fala casual, acolhe narrativas pessoais dramatizadas ao longo da entrevista. Dentre os estilos de fala em entrevistas sociolinguísticas, é o mais casual possível. No entanto, como aponta Labov (2001), obter narrativas pessoais em entrevistas sociolinguísticas é bastante complicado devido ao Paradoxo do Observador ${ }^{14}$. Por conta disso, o entrevistador precisa usar certas estratégias que permitam uma queda no nível de formalidade da entrevista, buscando promover uma conversa em que o vernáculo possa surgir. De acordo com Dantas e Gibbon (2014, p. 149):

[...] o estímulo às narrativas [...] representa uma estratégia para que o falante, ainda que esteja em situação de entrevista, desenvolva um estilo casual, isto é, uma forma de falar com menos audiomonitoramento que se aproxime, em alguma medida, do estilo vernacular, o estilo referencial do estudo variacionista laboviano.

Vencendo-se o desafio de obter narrativas, surgem questões referentes à sua natureza. Nem sempre o informante-narrador é o protagonista das narrativas, isto é, nem sempre as narrativas são de experiência pessoal. As narrativas nas entrevistas podem ser vicárias: o informante narra fatos acontecidos com outras pessoas. Além disso, observamse nas entrevistas o que se poderia denominar pseudonarrativas: relatos breves que não narram um evento por completo. Seguindo-se a configuração binária da Árvore (nos eixos fala casual, fala monitorada) e a definição laboviana do contexto Narrativa, o que fazer com as narrativas vicárias e as pseudonarrativas? Outra questão é a de que nem sempre as narrativas de experiência pessoal implicam o envolvimento emocional do informante e o menor monitoramento da fala. Por outro lado, há pseudonarrativas e narrativas vicárias que despertam o envolvimento emocional do entrevistado, podendo, portanto, instanciar fala casual.

O terceiro nó é o Língua, um contexto de fala monitorada. Refere-se a "questões sobre gramática, o posicionamento em relação a Filadélfia, o dialeto da cidade, e a língua em geral, assim como a aplicação de pares mínimos." (LABOV, 2001, p. 90, tradução

14 Labov (2008) assim enuncia o Paradoxo do Observador: "o objetivo da pesquisa linguística na comunidade deve ser descobrir como as pessoas falam quando não estão sendo sistematicamente observadas - no entanto, só podemos obter tais dados por meio da observação sistemática." (LABOV, 2008, p. 244). 
- Alternância de estilo em entrevistas sociolinguísticas: uma aplicação dos critérios da Árvore de Decisão laboviana

nossa ${ }^{15}$. Como veremos adiante, comentários sobre a linguagem levam naturalmente a um estilo de fala reflexivo e cuidado, razão pela qual o estilo contextual Língua não se apresenta como um grande desafio à identificação de estilos de fala.

O nó Grupo, quarto contexto da Árvore, abriga falas do informante com o entrevistador, fora da entrevista, ou com terceiros, presentes no local da entrevista. Equivale, na metodologia pioneira de Labov (2008), ao contexto A (ver nota 2). De modo geral, o uso desse critério não representa um desafio. Se eventualmente o informante conversa com terceiros, adota um estilo casual de fala, já que as entrevistas ocorrem em lugares familiares ao informante e nos quais transitam pessoas com quem ele tem alguma intimidade.

O quinto nó da Árvore é o Soapbox, situado do lado esquerdo, onde estão os estilos de fala monitorada. Caracteriza-se "por opiniões de cunho geral, não restritas ao contexto interlocutor-entrevistador, mas direcionadas a uma audiência maior. As principais características deste nó são a repetição e uma elevação no nível de intensidade (LABOV, 2001, p. 91, tradução nossa' ${ }^{16}$ ).

Schilling-Estes (2007), talvez pela menção de Labov ao volume elevado e à retórica repetitiva desse tipo de fala, interpreta Soapbox como um estilo de fala em que se fazem fortes afirmações sobre, por exemplo, visões políticas, valores pessoais, familiares e culturais. O desafio na identificação do estilo contextual Soapbox concerne ao fato de que as opiniões nem sempre são gerais, tampouco são manifestadas com afirmações fortes. A esse respeito, Valle e Görski (2014, p. 109) observam que "[...] justamente nos contextos em que a informante expõe suas opiniões pessoais sobre temas de família e/ou polêmicos, ela mostra maior envolvimento com a temática, inclusive elevando seu tom de voz [...]".

Esse descompasso entre opinião de cunho geral e opinião pessoal dificulta a segmentação de trechos Soapbox, o que pode levar o analista a anotá-los como Residual, sobrecarregando essa categoria de segmentação. Sente-se falta de um nó contextual para as opiniões pessoais na Árvore. No entanto, havendo esse nó, ele seria de fala casual ou monitorada? Levando-se em conta o observado por Valle e Görski (2014), opiniões pessoais poderiam ser situadas no eixo casual, desde que se verificasse o envolvimento emocional do informante e a presença de variáveis mais frequentes na fala casual.

15 No original: "questions about grammar, attitudes towards Philadelphia, Philadelphia dialect, and language in general, as well as minimal pairs.".

16 No original: "is characterized as an extended expression of generalized opinion, not spoken directly to the interviewer, but enunciated as if for a more general audience. The chief characteristics are an elevated volume level and a repetitive rhetoric.". 
O sexto nó da Árvore, Infância, abriga "relatos sobre jogos, experiências de infância, e assim por diante. [...] Um adulto pode falar sobre a sua infância sob uma ótica madura, ou infantil. É o último ponto de vista que queremos separar como um componente da fala espontânea." (LABOV, 2001, p. 91, tradução nossa $\left.{ }^{17}\right)$. Segundo Dantas e Gibbon (2014) e Valle e Görski (2014), esse nó poderia contemplar também as narrativas relacionadas à infância. O tempo e a perspectiva assumidos na fala, se da criança, pelo olhar infantil sobre a situação, distinguiriam Infância de Narrativa. Como veremos adiante, contudo, esse critério não soluciona por completo a distinção entre Infância e Narrativa, de um lado porque a própria Narrativa como estilo contextual desafia o analista na sua identificação, de outro porque a ótica madura e a ótica infantil podem mesclar-se em relatos sobre infância.

O sétimo nó da Árvore é o Tangente, de fala casual, referente a trechos em que o entrevistado produz "um corpo extenso de fala que desvia completamente do último tópico introduzido pelo entrevistador e representa um forte interesse do entrevistado" (LABOV, 2001, p. 92, tradução nossa ${ }^{18}$ ). Pela definição de Labov (2001), a identificação da fala tangente implica diferenciar trechos conduzidos ora pelo entrevistado, ora pelo entrevistador, distinguindo-se quem está no controle da interação. Assim, são tipicamente tangentes trechos que se afastam, em termos de temática, do tópico proposto pelo entrevistador e relacionam-se a atividades de fala inauguradas e desenvolvidas pelo próprio informante. Schilling-Estes (2007) afirma, entretanto, que, embora esperemos uma diminuição de monitoramento da fala quando o informante tangencia o tópico proposto pelo entrevistador, esse não é sempre o caso. Novamente com o exemplo da informante Felícia, a autora observa o uso predominante de variáveis peculiares ao inglês padrão quando a informante aborda, no tangenciamento, o tópico "educação em nível Superior e ingresso numa faculdade". Esse tópico leva Felícia a usar variáveis mais frequentes na linguagem padrão para afirmar sua capacidade de ingressar numa universidade e cursar Ensino Superior.

O último nó da Árvore é o Residual, de fala cuidada, correspondente a trechos da entrevista que não se encaixam em nenhum dos demais nós. O pressuposto é o de que se não instanciam fala casual alocada nos quatro contextos casuais da Árvore (Narrativa, Grupo, Infância, Tangente), os trechos que tampouco sejam contextos de

\footnotetext{
17 No original: "[...] topics of kids' games, kids' experiences, and so on. [...] An adult can talk about children's experience on this topic from an adult point of view, or from the kids' point of view. It is the latter that we want to set aside as a component of the casual speech.".

18 No original: "an extended body of speech that deviates plainly from the last topic introduced by the interviewer, and represents the strong interest of the speaker".
} 
- Alternância de estilo em entrevistas sociolinguísticas: uma aplicação dos critérios da Árvore de Decisão laboviana

Resposta, Língua e Soapbox devem ser alocados em Residual, isto é, em um eixo de fala cuidada por ocorrerem em uma entrevista. O contexto Residual é discutível por abarcar trechos de naturezas distintas, produzidos com diferentes graus de atenção à fala, e que eventualmente podem instanciar variáveis vernaculares. Em outras palavras, as entrevistas podem conter trechos segmentados como Residual pelas razões acima, mas que têm um estilo mais casual de fala, como é o caso de opiniões pessoais, narrativas não pessoais, entre outros.

A despeito das críticas $^{19}$ recebidas pela Árvore e dos desafios para utilizá-la, os pesquisadores do LínguaPOA (2015-2019) vêm aplicando os critérios da Árvore na anotação da trilha Estilo nas transcrições das entrevistas. Entende-se que, se as entrevistas forem usadas para extrair dados na análise dos padrões de produção de diferentes variáveis linguísticas, a anotação na trilha Estilo poderá subsidiar o controle de mais uma variável previsora, Estilo Contextual, o que, por seu turno, auxiliará a esclarecer a variação linguística intrafalante.

\section{Aplicação dos critérios da Árvore de Decisão a transcrições do LínguaPOA}

A segmentação das transcrições do LínguaPOA (2015-2019) em diferentes estilos contextuais implicou examinar, inicialmente, o roteiro de entrevista do LínguaPOA, com o intuito de entender a natureza das perguntas e das possíveis respostas. O roteiro contém perguntas voltadas à produção de narrativas pessoais (Já correste algum risco de vida? Se sim, qual? O que aconteceu? Se não, conheces alguém que já correu? O que houve?), avaliações (Como é o trânsito em Porto Alegre?), descrições (Há quanto tempo moras neste bairro/local? Gostas do lugar? Como era antigamente?), opiniões para assuntos como política, violência urbana, uso de drogas, entre outros (O que achas dos políticos brasileiros em geral? Tu achas Porto Alegre violenta? Na tua opinião, quais são as causas da violência? Qual é a tua opinião sobre a descriminalização do uso das drogas?).

\footnotetext{
19 Entre as críticas aos critérios da Árvore de Decisão laboviana encontradas na literatura, está a de Baugh (2001), sobre a organização binária na Árvore (fala casual vs. fala cuidada). Para esse autor, cada ramo da Árvore deveria refletir uma tendência, não uma oposição, já que a mescla, não a separação de formalidade e informalidade aparecem frequentemente em entrevistas sociolinguísticas. Já para Eckert (2001), os estilos contextuais da Árvore de Decisão laboviana relacionam-se a subeventos das entrevistas sociolinguísticas de diferentes naturezas: o estilo contextual Resposta é definido com base em seu "lugar" na sequência da fala; os estilos Língua e Infância, com base em tópicos sobre que se fala; os estilos Soapbox e Narrativa, com base em gêneros discursivos; o estilo Grupo, com base na audiência. A diferente natureza dos subeventos torna desafiadora a tarefa de identificar alternância de estilos contextuais nas entrevistas sociolinguísticas. No entanto, como afirma Eckert (2001), a preocupação de Labov (2001) ao propor a Árvore não é a de definir estilo, mas a de identificar, arranjar e controlar subeventos de fala - que Labov (2001) considera estilos contextuais - associados à variação linguística nas entrevistas, razão de adotarmos os critérios da Árvore na anotação das entrevistas do LínguaPOA.
} 
Eliciam-se respostas com opiniões genéricas e opiniões pessoais, para perguntas sobre, por exemplo, violência e política. Há perguntas sobre a infância e costumes antigos, como celebrações de Natal, Páscoa e aniversários, que tendem a ser respondidas pelos informantes com relatos no estilo contextual Infância. Esses dois contextos, Infância e Soapbox, localizam-se bem nas entrevistas do LínguaPOA a partir das perguntas. Contudo, há estilos contextuais que não são desencadeados por perguntas específicas. Por exemplo, as narrativas são produzidas ao longo de toda a entrevista, a qualquer momento. Como afirmamos acima, não há uma pergunta sobre língua no roteiro, e o estilo contextual Grupo é pouco frequente nas entrevistas do acervo.

Esse reconhecimento inicial das perguntas no roteiro permitiu construir alguns critérios de segmentação, o que contribuiu para minimizar discrepâncias na aplicação dos critérios da Árvore de Decisão pelos pesquisadores. Ilustram-se a seguir os desafios por eles enfrentados na aplicação dos critérios da Árvore e as estratégias usadas pela equipe para superá-los, partindo-se do primeiro nó da Árvore, do estilo contextual Resposta.

Em um primeiro momento, os pesquisadores registravam como Resposta todo o trecho que respondia diretamente à pergunta do entrevistador, o que poderia ser um trecho de fala bastante longo, contemplando inclusive outros estilos contextuais. Isso decorreu do fato de os informantes do LínguaPOA tenderem a contextualizar suas respostas com longos trechos de fala, correspondentes a pré-sequências, conforme Marcuschi (2003). Esse padrão de segmentação foi posteriormente revisado pelos pesquisadores. Decidiuse seguir à risca o critério de Labov: segmentar como Resposta apenas o primeiro trecho imediatamente após a fala do entrevistador, o que compreende apenas o início das présequências, quando elas ocorrem.

Nos excertos ${ }^{20}(1)$ e (2) e todos os demais, os trechos anotados como Resposta estão sublinhados. O excerto (1) mostra a segmentação do estilo contextual Resposta inicialmente praticada pela equipe: o trecho que respondia à pergunta do entrevistador em sua íntegra. Já o excerto (2) ilustra a segmentação para Resposta posteriormente adotada pelos pesquisadores, seguindo-se exatamente a definição de Labov (2001).

\footnotetext{
20 A transcrição dos excertos apresentadas neste artigo não corresponde fielmente ao sistema de transcrição em ELAN das entrevistas do LínguaPOA. Esse sistema seguiu a orientação geral de Oushiro (2014, p. 130): dar preferência a "[...] um sistema mais simples de transcrição - por exemplo, sem o uso (ou abuso) de caracteres como dois pontos, chaves, parênteses, maiúsculas...". Para o presente artigo, inspiramo-nos em parte nas normas de transcrição do NURC, disponíveis em obras como a de Hilgert (1997), por exemplo, para apresentar os excertos em um formato de texto passível de leitura por um público maior, não especialista.
} 
- Alternância de estilo em entrevistas sociolinguísticas: uma aplicação dos critérios da Árvore de Decisão laboviana

D: Como é que tu escolheu essa área?

S: Ah, quando eu tinha:: / eu tava no colégio... eu tava no/ acho que no meu... se foi no terce(i)ro ano, eu tava em dúvida entre direito e jornalismo, porque sempre gostei muito de escrever, sempre tive muita facilidade, assim. E::/ só que eu achava, né/ eu tô falando como é que foi meu raciocínio na época, TÁ? Talvez não seja o que penso hoje, mas, na época, eu achava o jornalismo assim, não fútil, mas, tipo, que eu não poderia faze(r) a diferença, eu achava que no direito assim, aquela coisa meio de faze(r) justiça e tal..., essa foi o motivo da escolha (LÍNGUAPOA, 2015-2019, Inf84)

D: Como é que tu escolheu essa área?

S: Ah, quando eu tinha:: / eu tava no colégio... eu tava no/ acho que no meu... se foi no terce(i)ro ano, eu tava em dúvida entre direito e jornalismo, porque sempre gostei muito de escrever, sempre tive muita facilidade, assim. E::/ só que eu achava, né/ eu tô falando como é que foi meu raciocínio na época, TÁ? Talvez não seja o que penso hoje, mas, na época, eu achava o jornalismo assim, não fútil, mas, tipo, que eu não poderia faze(r) a diferença, eu achava que no direito assim, aquela coisa meio de faze(r) justiça e tal..., essa foi o motivo da escolha. (LíNGUAPOA, 2015-2019, Inf84)

No excerto (1), é possível notar que a resposta fica longa porque o informante usa uma pré-sequência em sua contextualização. Mesmo que somente o conteúdo em itálico respondesse à pergunta, o trecho todo foi inicialmente segmentado como Resposta, pois entendeu-se que todo ele oferecia informações consideradas relevantes pelo informante para responder à pergunta. O excerto (2) mostra que, com a nova anotação, a maior parte da fala do informante cai no nó Residual, o que levanta a questão: em que parte da Árvore deveriam ficar os trechos cujo conteúdo responde a uma pergunta, mas não correspondem ao estilo contextual Resposta?

Na segmentação dos estilos contextuais nas transcrições do LínguaPOA, a equipe avalia pontualmente cada trecho segmentado como Resposta. Para tanto, leva em conta o desenrolar da interação entrevistador-informante. Por exemplo, se a pergunta do entrevistador interrompe a atividade de fala do informante, observa-se a reação do informante à interrupção: esse pode alinhar-se ao entrevistador, abandonando aquilo sobre o que falava para desenvolver temáticas introduzidas, na pergunta, pelo entrevistador; ou, após responder a pergunta de forma breve, o informante pode voltar à atividade e ao assunto sobre o qual falava antes da pergunta. No primeiro caso, o trecho inicial da fala do informante será anotado como Resposta; no segundo, será anotado conforme o estilo contextual que o informante vinha desenvolvendo antes da intervenção do pesquisador.

Sente-se falta na Árvore, portanto, de critérios que orientem a segmentação de trechos maiores de fala do informante na elaboração das respostas, mas não se encaixam em contextos da Árvore que não o Residual. Além disso, como afirmamos acima, os 
critérios da Árvore não contemplam ecos e feedbacks, muito frequentes nas entrevistas sociolinguísticas e facilmente confundíveis com os trechos que deveriam ser segmentados como Resposta. Para o caso específico das entrevistas do LínguaPOA, decidiu-se alocar tais trechos no contexto Residual.

O excerto (3) traz, em itálico, um trecho no estilo Narrativa. Trata-se de um relato pessoal prolongado e dramatizado, de uma situação vivenciada na trajetória escolar do informante. Em meio à narrativa, o entrevistador faz um eco (em negrito), ajudando o informante a lembrar o nome da universidade em questão (UNISINOS). O eco ocorre em meio à Narrativa, razão pela qual se optou por segmentá-lo como Residual e, logo em seguida, manter a segmentação anterior, isto é, Narrativa.

(3) D: E:: na tua escola da época de infância, lembra de alguma situação? Gostava de ir na escola? Tinha amigos da escola? Como é que era?

S: Assim ó, o colégio Anchieta, eu estudei lá no Anchieta. E o Anchieta era pro pessoal pobre que não tinha condições de pagar, sabe? Toda a parte de baixo ali do Anchieta era o pessoal que não tinha condições de pagar, então ele era gratuito, ele era estadual né, assim né, digamos assim. E a parte lá de cima, que hoje é o ginásio, toda aquela parte de cima do Anchieta ali era pros ricos, era pra quem pagava, então nós/ todo mundo estudava ali na parte de baixo, mas o ensino ali era muito bom ali assim, era muito. Só que a professora que nós tínhamos, ela só botava no quadro assim/ as outras professoras de primeira à quarta série, quinta série, ensinavam mais, mas a MINHA professora não me ensinava, a minha professora só passava ã no pátio com nós o dia inteiro brincando na praça. Nós atravessava pro o(u)tro lado da rua, aonde é aquele esse que fizeram agora, aquele colégio novo ali, agora que fizeram

D: A Unisinos

S: A Unisinos, isso. Ali tinha um pátio grande, ali tinha uma praça, aí nós chegava na sala de aula, ela escrevia assim "o dia hoje está com sol, olha, vocês tão vendo escrevi isso aqui, tá, então tá, deixa o material de vocês guardado e vamos pro pa pra praça brinca(r)", e a gente ia pra praça brinca( $r$ ), atravessava pro outro lado da rua, ia pra praça às cinco horas da tarde, a gente voltava e daí pegava nossas mochilinha e ia pra fila, tocava a campainha e a gente ia embora né. Então a gente não aprendeu até a quarta série, eu não aprendi nem le(r), nem escreve( $r$ ), nem nada, porque a professora só fazia isso, mas meus outros amigos, meus colega, minha prima, o pessoal que tava em outras salas aprenderam a escreve( $r$ ), e eu não aprendi. Daí o colégio ã fecho(u) essa parte ali que era pro pessoal pobre, a gente passou a estuda(r) lá na escola Bahia, que era próxima dali, mas daí eu tendo já na quarta série, eu tive que volta(r) pra primeira série, porque eu não tinha aprendido a le( $r)$ nada, nem eu, nem meu irmão, nem uma outra prima que tava comigo também na mesma sala, também porque a professora não ensinava. (LíNGUAPOA, 2015-2019, Inf10)

A segmentação de trechos no estilo contextual Narrativa efetuada pela equipe LínguaPOA segue parcialmente o modelo laboviano. Para Labov (2001), o estilo corresponde apenas a narrativas pessoais dramatizadas. Já a opção da equipe foi segmentar trechos narrativos, pessoais ou não, no estilo contextual Narrativa quando evidenciassem envolvimento emocional, isto é, quando fossem dramatizados e tivessem uma extensão 
- Alternância de estilo em entrevistas sociolinguísticas: uma aplicação dos critérios da Árvore de Decisão laboviana

relativamente longa, sem pausas ou hesitações. Seguindo-se Dantas e Gibbon (2014), decidiu-se não anotar como Narrativa os relatos curtos e não dramatizados, em que predomina a fala monitorada e que não correspondem à contação de uma história. Em sua maioria, essas pseudonarrativas apenas respondem a uma pergunta do entrevistador de forma um pouco mais detalhada. Já relatos vicários - longos e dramatizados, feitos em fala casual, muitas vezes surgidos pelo interesse do informante, mostrando tanto uma relevância tópica, quanto uma proximidade do informante com o protagonista da história - são segmentados como Narrativa. No excerto (4), em itálico, observamos um exemplo disso: a informante narra a escolha profissional e a trajetória acadêmica dos seus filhos.

D: E os teus outros filhos fazem o quê?

S: O meu mais ve/ esse é do meio, o meu mais velho também fez a mesma coisa, ele também é professor de educação física, só que os dois fizeram faculdade ju/ um/. Eles têm uma ano de diferen/ um ano e três meses de diferença, aí quando o mais velho fez vestibular, que ele era, assim, o meu mais velho assim ... sempre de boa, sempre vai da(r) tudo certo, nunca foi se/ nunca se preocupo(u) muito com as coisas assim, não é de inculca(r). Então ele di/ ele/ ele pego(u) e disse que:: que ia faze(r) vestibular, né, pra educação física. E não/e nem estudo(u), co/basicamente, e passo(u). Aí o o(u)tro, um ano depois, era a vez dele e ele não sa/tava em dúvida. E aí ele disse "Ah, vou fazer educação física, se o Diego passo(u), eu passo também", porque esse era mais preocupado ((risos)), né, e estudava mais. Daí "Se ele passo(u), eu passo também", e passo(u). Aí eles fizeram praticamente juntos, porque o mais velho tava no primeiro semestre/ primeiro ano. Ele fez, ã, quartel né, o C.P.O.R. e o/ e aí ele rodo(u) em várias cadeiras, porque ele não conseguiu fazer tudo. Também não é/ não é de ficar, de estuda(r) né, é aquela coisa fez, fazia men(a)s, né. Eles são muito assim o/ os dois de assisti(r) e aprende(r), eles/ eles/ eles memorizam só de ve(r), de/ né, não, ah, não são muito de fica(r) anotando e fica(r) lendo. E daí o/ aí ã/ aí ele foi se atrasando, e o outro começou a $i(r), a, n e ́$, corre $(r)$, corre(r) pra se formarem juntos e daí se formaram juntos. (LíNGUAPOA, 2015-2019, Inf90)

O estilo contextual Língua ocorre muito esporadicamente nas entrevistas do LínguaPOA, visto que não há uma seção específica no roteiro sobre o assunto, tampouco a leitura em voz alta de pares mínimos. Há apenas algumas manifestações espontâneas sobre a linguagem dos porto-alegrenses em todo o corpus, em respostas a perguntas sobre a relação dos entrevistados com a cidade de Porto Alegre, sobre seus habitantes, sobre idiomas.

O excerto (5) ilustra um trecho segmentado como Língua (em itálico). Nele, o informante apresenta sua percepção dos diferentes falares da cidade, ressaltando a maneira de falar dos bairros centrais de Porto Alegre, como Bom Fim e Cidade Baixa, e comparando os falares da zona central e da zona sul da cidade. Para esses casos, a segmentação do nó se deu a partir da proposta de Labov (2001), como fala monitorada. Observem-se as hesitações, as dúvidas e o cuidado na busca de termos, evidenciando o monitoramento da fala. 
D: Â:: tu percebe diferença ... no comportamento das pessoas ã:: ... de bairro pra bairro, região pra região, assim?

S: Ah, com certeza, $[$ com certeza.

D:

[Na zona norte, zona sul, zona leste. ( )

S: Depois que tu treina o olhar, tu não tem como não nota(r), né.

D: Que que tu comentarias assim de?

S: $\tilde{A}:$ : na zona sul, eu percebo muito que o:: que o a:: ..., pelo menos a língua/, é tipo eu não sei se são os termos ou se é o sotaque, mas tem, mas tem termos muito específicos que se usa tipo no Bom Fim, e tem termos específicos que se usa no na Cidade Baixa. Tem um jeito de de de fala(r) específico do:: ali daquele miolo da Oswaldo Aranha tem/, e é muito diferente por exemplo do:: do:: ... do estilo de fa/de fala do pessoal da zona sul, que é mais tranquilo assim, que é mais espaçado, que não é tão:: tão "BAH, E AÍ GURIA, a gente, bah, se viu na redença". Então é mais/é mais que nem o meu, porque eu/ eu moro na zona sul há dezoito anos, então ele é mais mais que nem o meu assim, mais que nem o meu sotaque. (LíNGUAPOA, 2015-2019, Inf132)

Assim como Língua, o estilo contextual Grupo não aparece com frequência nas gravações das entrevistas do LínguaPOA, pois, para realizar as entrevistas, os pesquisadores marcavam antecipadamente um horário com os informantes que, geralmente, estavam sozinhos quando recebiam o entrevistador. Em (6), está um trecho no estilo Grupo em que a informante interage com uma amiga sua, presente no local da entrevista. As duas debatem sobre qual zona de Porto Alegre é melhor para morar, se a zona sul ou a zona norte. Apenas a parte inicial está apresentada, devido à longa duração do trecho (em torno de cinco minutos). Contudo, (6) ilustra bem um segmento no estilo contextual Grupo, de acordo com a Árvore de Decisão laboviana.

(6) D1: Tu gosta dessas zonas?... Qual é a tua preferida?

S1: Bairro?

D1: Das zonas... a norte, a sul, a leste e a central.

S1: Não, é norte ou sul... E hoje em dia, eu nem sei te dize(r) mais direito assim, porque... eu moro há muitos anos aqui também, mas eu gosto muito da zona norte.... Eu/ eu/ eu/ eu gosto mais daqui assim, em matéria de qualidade de vida.

D1: Uhum

S1: Mas a zona norte pra/ pra ti sai::(r), pra ti i(r) em supermercado, padaria, tudo tem lá, aqui não tem tudo isso, tudo muito longe... né?

S2: Ah, eu acho que aqui tem tudo.

S1: MAS DA [ONDE?

S2: $\quad[$ Tem tu::do, eu vou no mercadinho ali da esquina, eu compro tudo que eu quero.

S1: É que, é que ela [nasceu aqui

S2:

[Eu quero/ eu não quero ir pra zona norte. [Tá louca?

S1: [Não, é que eu não gosto de mercadinho de esquina. Eu quero u::m supermercado decente, não tem. 
- Alternância de estilo em entrevistas sociolinguísticas: uma aplicação dos critérios da Árvore de Decisão laboviana

S2: Tu não fala mal da zona sul.

S1: ((risos)) Viu? É que ela nasceu [na zona sul.

'S2:

é tudo de bom.

[Eu acabei de dizer pra ela, a zona sul

S1: Não, ela é tudo de bom, mas eu/ eu prefiro... que tem tudo é a zona norte.

S2: Pra mim, aqui tem tudo, eu quero pão, vou ali na esquina. [...] (LínGUAPOA, 20152019, Inf119)

Sobre o estilo contextual Soapbox, nota-se que há uma tendência nas entrevistas do LínguaPOA de os informantes emitirem opiniões pessoais, não opiniões gerais com afirmações fortes. Por essa razão, Teixeira (2020) propôs uma divisão desse nó em duas categorias: de um lado, Soapbox conforme a definição de Labov (2001) e, de outro, um novo nó denominado Posicionamento - esse último contemplando trechos de fala em que os informantes expressam opiniões pessoais. Essa medida tiraria as opiniões pessoais do nó Residual.

Os excertos (7) e (8) apresentam, respectivamente, um trecho de fala no estilo contextual Soapbox e um caso daquilo que se poderia considerar Posicionamento.

D: Tem uma questão aqui, já que a gente falou no/ no assunto, seria sobre a descriminalização do uso das drogas ... que que tu acha disso?

S: Das o QUÊ?

D: Descriminalização do uso das drogas, legalização... Acha que seria uma/ uma [forma de combater à violência?

S: [Mas de todas as drogas? Acho que tu tá te referindo mais à maconha que que eles querem né? ... Aí tem que especificar não é as drogas em geral.

D: Eh, é que tem pessoas que defendem que teria que liberar tudo... Algumas pe/ pessoas acham que a maconha seria uma que já poderia ser liberada e outras não... $\mathrm{Na}$ tua opinião [qual seria?

S: $\quad$ [Eu acho que é loucura porque a droga mata né? ... E tu escolhe qual é que mata mais rápido.

D: Sim..., então não seria uma boa?

S: Eu não se/ ã, da maconha eu não sei se é uma boa porque... eu não sei não sei te dizer mesmo no Uruguai é libera:do né, tem todo crité::rio para usa(r), mas tu acha que vão... tu acha que vão segui:r os crité::rios de ve:nda de/... ((respira fundo)). Eu não sei, não sei viu, acho que... poderia ser usado que a/ ã a maconha tem um aspecto medicina:l, né?... eu acho que poderia ser usado então numa indicação MÉDICA, né?... Mas não como eles tão querendo, ou como é feito..., qualquer pessoa pode... usar tanto, comprar tanto, né.

D: Então só legalizar não [seria a resolução do problema. 
S: $\quad$ [Nã::O.... Eu acho que não, porque/porque é o caminho, viu?... Mu:ito dependente... começa com a maconha... Eu acho que seria ó, excelente se fosse através de.: assim... uma indicação médica né... com orientação... E tem determinados casos termina:is né.... é indicada a maconha, porque ela alivia né... mas, por quê? Muita drogadição COMEÇA com a maconha, porque ela te deixa alienado... te deixa viajando... não é bem assim... Se a pessoa tá infeliz vai/ ... vai atrás de alguma coisa que dá alívio. (LíNGUAPOA, 2015-2019, Inf18)

D1: E tu consegue perceber alguma diferença entre essas zonas, assim, nas pessoas, [comportamento, jeito de falar, de vestir?

S1: $\quad[$ sim, sim, sim sim sim sim sem dúvida. Aqui no... no zona norte, aqui não tenho nem dúvida. Aqui na zona norte as pessoas se falam na rua como se fossem gente. Né:: ali no... bairro Petrópolis, ali/ Bela Vista por exemplo, ali é::... tá mais pra desfile de moda aquilo ali:: eh talvez por causa da classe... do pessoal de Bela Vista, classe alta [...] ali as pessoas se falam assim, é tudo assim, aquela co::isa assim... dista::nte né::. Aqui não, aqui tu te sente à vontade. Parece que tu tá na... tá em casa, conversando com as pesso::as e ta::l... faz amizade com os vizi::nhos assim/lá não, tu faz ah/ quem é aquele cara? Di(z)/ a::h não sei. Quem é? A::h nãa::o, ele/ pois é:: ã essa pessoa não se::i, tem que ve(r) quem é. Não, aqui eu olho/ nã:::o aquele alié o fulano que é a :.... que é tio do Bento/ tá aí, veio visi/fazer uma visita/opa, esse cara eu não conheço. Já to/ ligo p(r)o conselho, já digo olha, entrou um carro estranho na rua aqui, a gente se conhece. Lá não, lá fica todo mundo/ é esse aí é alguém no::vo que tá aí... ninguém sabe, ninguém conhece ninguém. É que nem meu pai diz, tem muito morador de apartamento/morador de apartamento não se fala entre eles. Os cara moram um do lado do outro e:: passam a::nos sem se fala(r) né... Aqui não, aqui parece que é uma coisa meio natura::L que acontece... eu acho é o perfil das pessoas que bu::scam esse tipo de espaço [...] (LÍNGUAPOA, 2015-2019, Inf45)

Nos excertos (7) e (8), é possível perceber a diferença entre os tipos de opinião. Em (7), há uma opinião bastante genérica acerca da descriminalização do uso das drogas, especialmente ao tratar da maconha, apresentando frases truncadas, hesitações, pausas, uso frequente do marcador discursivo 'né', frases prontas sobre o tema - um caso de intertextualidade, conforme Schilling-Estes (2004). A informante fala como se estivesse dirigindo-se a uma plateia, de maneira mais monitorada. O excerto (8), por sua vez, traz uma opinião bastante pessoal. $\mathrm{O}$ informante expressa as diferenças que percebe entre certos bairros, emitindo juízos de valor, o que evidencia o forte envolvimento que o informante tem com o bairro onde mora. É possível perceber o uso de um estilo mais casual principalmente nas falas reportadas, quando o informante muda o tom de voz para interpretar situações fictícias, que representam a diferença entre os bairros. O trecho de fala em (8) seria alocado no contexto Posicionamento, proposta ainda em avaliação pela equipe de pesquisadores. Entretanto, é importante destacar que Posicionamento abrigaria opiniões pessoais, as quais exibem, entre outras características, a tendência de serem enunciadas em linguagem mais casual. 
- Alternância de estilo em entrevistas sociolinguísticas: uma aplicação dos critérios da Árvore de Decisão laboviana

Quanto ao estilo contextual Infância, observam-se nas entrevistas do LínguaPOA relatos em que está presente o ponto de vista do adulto, não da criança. Esses não podem ser segmentados como Infância, de acordo com Labov (2001). Nas transcrições do LínguaPOA, relatos narrativos sobre o tempo de criança são anotados como Infância apenas quando invocam a ótica infantil. Quando a ótica é a do adulto, anotam-se os relatos como Residual. Trechos em que se mesclam ambas as óticas implicam múltiplas segmentações, alternando-se os respectivos contextos, Infância e Residual, o que é bastante desafiador para quem anota a trilha.

O excerto (9) é um trecho de fala sobre o tópico Infância, mas não se desenvolve do ponto de vista da criança. Nele, há pouco envolvimento emocional do informante com o que fala e é expressiva a ocorrência de "ã", indicando monitoramento da fala. Além disso, o informante usa as palavras "sorte" e "privilégio" para veicular o julgamento que ele, enquanto adulto, faz daquela época, e as palavras "usufruía" e "embora", que apontam um uso mais formal da língua. O trecho foi, por essas razões, anotado como Residual.

D: A gente tem uma pergunta aqui sobre a infância, tu/ como que era tua infância? Que tipo de coisa tu fazia com os amigos?

S: A minha infância foi ã/ foi muito boa. Ã::... eu tive a sorte de mora(r) perto dum parque aqui. Eu more/ eu nasci aqui perto, aqui na/ no Moinhos de Vento. Então eu ã::/ eu ia muito a parques ... ã::m tinha/, eu nasci numa época que era bastante seguro ainda fica(r) na rua, sozinho, sem pais, então a gente ã, digamos que eu usufruía muito, tinha mui/ muitas crianças na minha rua, era uma rua pequena também, então a gente brincava ali na rua, esconde-esconde, essas coisas tudo, skate, ã::m. E:: também acho que tive... ã o... privilégio de ter tido bastante oportunidade de/ de lazer assim, no sentido, tinha uma casa duma vó numa praia, então passava verões ã::, dois meses na praia. Tive/ o meu pai é um cara que, embora tenha ã... não dado muito certo em algumas áreas, ou falhado em algumas áreas assim que a gente espera às vezes dum pai, ele foi um cara muito interessante no/ na parte assim de lazer, de acompanha(r)... Â:: então ele sempre me levou a muitos programas [...]. (LíNGUAPOA, 2015-2019, Inf81)

Já no excerto (10), o tempo de criança é abordado a partir de um ponto de vista infantil, o que confirma sua anotação no estilo Infância. O único desafio aqui é diferenciar Narrativa de Infância, como apontado anteriormente: anotam-se em Narrativa os relatos de experiências pessoais na infância, e como Infância as enumerações de jogos, brincadeiras e circunstâncias relacionadas. D: E como tu, assim, viu mudar o bairro? Tu vê/ viu mudanças assim
[antigamente? 
S: [lh:::, quando eu na/ quando eu era criança não tinha o Iguatemi. Não tinha todas essas casas, esses negócio(s) tudo pra lá não existia nada, era tudo... assim, ã::, terrenos e terrenos, mato, era uma chácara pra lá. E:: eu e meu ir/ meus, meus irmãos/ a minha mãe, a minha mãe:: costurava pra fora, e às vezes a gente ficava... em volta dela e brigando, discutindo, ela dizia "Ai, vão da(r) uma volta". A gente ia fazer piquenique, a gente pegava um/ u::ma sacola, botava uma toalha, pegava um pão, que a minha mãe fazia um pão doce bem legal, e:: um suco, e a gente ia caminhar, né. Daía gente caminhava, daía gente chegava perto duma árvore assim... botava uma toalha, subia na árvore, brincava e brincava, depois sentava, comia e voltava ... pra casa. (LíNGUAPOA, 2015-2019, Inf90)

O estilo contextual Tangente fica no eixo de fala casual da Árvore. Segmentá-lo é relativamente complexo devido ao alto grau de subjetividade na sua identificação, fato já antecipado por Labov (2001). Nas entrevistas do LínguaPOA, a diferenciação entre Residual e Tangente levanta dúvidas. Em alguns trechos, o informante introduz um novo tópico, porém de alguma forma relacionado com o tópico inserido pelo entrevistador. Em outros, o tangenciamento é breve, o informante retoma o tópico do entrevistador em seguida. Diante dessas situações, os pesquisadores do LínguaPOA levantam questões sobre os limites entre Residual e Tangente: é preciso que o assunto trazido pelo entrevistado desvie por completo do assunto anterior? Caso desvie, mas não completamente, o trecho seria segmentado como Residual ou como Tangente? E em relação à duração do tangenciamento, deve ser prolongado?

No excerto (11), está em itálico um trecho de entrevista do LínguaPOA segmentado como Tangente. Sua identificação foi desafiadora, pois, no tangenciamento, o informante introduz um assunto específico, sobre um aspecto da escola comunitária. O assunto da escola, porém, já havia sido abordado pelo informante antes, em outro momento da entrevista. Como Schilling-Estes (2007) constata, o informante controla, com essa retomada (breve) de um tema anterior, o footing (desenrolar de temas) da interação: o informante explica o funcionamento de sua ONG e, em seguida, foca em um aspecto para além do funcionamento da escola, apesar de, em linhas gerais, manter-se no tópico proposto pelo entrevistador.

D: A ONG em si ... ã sobrevive como, assim? 
- Alternância de estilo em entrevistas sociolinguísticas: uma aplicação dos critérios da Árvore de Decisão laboviana

S: É a ONG/ a/ a ONG/ nós tinha/ nós temo/tínhamos/, no caso, nós tínhamos um projeto com o município, né que se chamava inclusão cultural. E um/ com o estado, que é ponto de cultura né, que a gente aqui é um ponto de cultura, mas com essa crise aí, que deu aí, tipo::, foi sustada essas verba, né. E também tem uma escola de educação infantil aqui que temo(s) uma meta de quarenta a sessenta alunos que o município repassa uma verba pra nós né, só que hoje nós (es)tamo(s) com oitenta e duas criança(s), né. $\mathrm{E} / \mathrm{e}:$ : o município/ quer dizer, (es)tamo(s) tentando negocia(r) com o município, ele repor essa diferença aí, né, que tá muito difícil assim pra gente. Eh, e/ e/ e, antes da crise, nós tinha, assim, uma média de setenta por cento dos pais colaboravam né, agora inverteu né. Agora é quinze, vinte por cento colaboram, e o resto não tem mesmo, não tem como né. E aí, por outro lado, também não tem como tira(r) a criança da escola, né. Então, assim, tá um/tá um colapso financeiro, assim, a escola, tá bem complicado, bem bem mesmo. Agora, pra essa semana, a gente vai até/ eh, (es)tamo(s) falando lá com ... a secretaria ou eles repassam o recurso pra nós né, ou vão ter que arrumar lugar pras criança(s). Esse excesso de criança né, não tem como, digamos a ONG manter né. Por mais que a gente tenha corrido atrás aí, não/ não tendo/ não (es)tamo(s) tendo muito sucesso. E a escola também é/ é/ é muito fértil assim, nós (es)tamo(s) com três menina também esperando bebê, né. Aí, tipo, já e/ e até tem um exemplo, bem assim, tipo, uma senho/ uma menina aí, a Diana, que ela tentou, assim, há cinco anos ter bebê, né, começo(u) trabalha(r) na escola, seis meses, se preparou pra ganhar o bebê, né. Então a escola tem essa coisa de/ de muito fértil, assim, a gente quando entra a gente já fica meio assim, "bah, ó, será que vem bebê aí, né?", mas é bem/ bem bacana mesmo o trabalho. (LíNGUAPOA, 2015-2019, Inf97)

Por fim, os excertos (2) e (9), acima, ilustram o estilo contextual Residual, que aloca todos os trechos de fala não contemplados pelos demais contextos da Árvore de Decisão. Como aponta Labov (2001) e já foi afirmado neste artigo, o desafio desse nó para o pesquisador é não o utilizar para abrigar todo e qualquer caso de dúvida na identificação de estilos contextuais na entrevista. É preciso lembrar que o nó Residual fica do lado esquerdo da Árvore, o dos estilos de fala monitorada. Examinar as variáveis prevalentes no trecho, se peculiares à fala cuidada ou casual, é uma medida relevante para evitar equívocos na segmentação desse estilo contextual.

\section{Últimas palavras}

A maior parte das decisões tomadas pela equipe de pesquisadores do LínguaPOA para identificar estilos contextuais nas transcrições das entrevistas do acervo conforma-se aos critérios da Árvore de Decisão de Labov (2001). Os ajustes nos critérios, relacionados a diferentes dimensões da interação (sequência, tópico, atividade e controle da fala, entre outros), ocorreram devido às características das entrevistas consideradas.

Entre as medidas tomadas pela equipe para unificar e adequar o trabalho dos diferentes pesquisadores na identificação e anotação dos estilos contextuais, estão: (a) considerar as perguntas do roteiro de entrevista; (b) distinguir tipos de opinião na segmentação de trechos de fala no estilo contextual Soapbox, com a proposta de 
eventualmente ampliar a Árvore com o nó Posicionamento, no eixo de fala casual; (c) ter cautela na atribuição de trechos ao nó Residual.

A equipe optou por segmentar todos os trechos da entrevista, incluindo-se feedbacks, ecos e certos contextos frequentes no acervo - falas que respondem diretamente à pergunta do entrevistador, comentários, avaliativos ou não, opiniões pessoais, entre outros. Assim como o nó Posicionamento, outros nós podem ser adicionados à Árvore, a depender da sistematicidade das características presentes nos trechos. Em outras palavras, concordamos com Labov (2001) quando ele aponta a necessidade de fazer a Árvore crescer, não de podá-la.

Por fim, é importante frisar que a reflexão sobre a segmentação de estilos contextuais aqui empreendida não traz respostas definitivas para questões que há muito se levantam sobre os critérios da Árvore de Decisão laboviana. Apresentaram-se possibilidades de aplicação e desenvolvimento desses critérios, inspiradas nas características do acervo em questão. O passo futuro da equipe LínguaPOA será, com base na anotação da trilha Estilo nas transcrições, codificar dados extraídos das entrevistas para estilo casual vs. estilo monitorado, por exemplo, no estudo de diferentes variáveis. Assim, a equipe terá uma medida tanto do efeito dos estilos contextuais sobre os processos variáveis, quanto da eficácia da própria segmentação efetuada.

Esperamos que este artigo possa auxiliar usuários do acervo LínguaPOA no acesso às transcrições das entrevistas e em análises de estilo contextual, bem como aqueles que enfrentam o desafio de identificar estilos em entrevistas sociolinguísticas, a partir da Árvore de Decisão laboviana.

\section{Referências}

BAGNO, M. Nada na língua é por acaso: por uma pedagogia da variação linguística. São Paulo: Parábola Editorial, 2007.

BAGNO, M. A língua oculta: língua \& poder na sociedade brasileira. São Paulo: Parábola Editorial, 2003.

BAUGH, J. A dissection of style-shifting. In: ECKERT, P.; RICKFORD, J. R. (ed.). Style and sociolinguistic variation. Cambridge: Cambridge University Press, 2001. p. 109-118. 
- Alternância de estilo em entrevistas sociolinguísticas: uma aplicação dos critérios da Árvore de Decisão laboviana

BELL, A. Back in style: reworking audience design. In: ECKERT, P.; RICKFORD, J. (ed.). Style and sociolinguistic variation. Cambridge: Cambridge University Press, 2001. p. 139-69.

BERBER SARDINHA, T. Linguística de corpus. Barueri: Editora Manole, 2004.

COUPLAND, N. Style: language variation and identity. Cambridge: Cambridge University Press, 2007.

DANTAS, W. S.; GIBBON, A. O. A abordagem de estilo de fala na proposta da "árvore de decisão": algumas questões de análise. In: GÖRSKI E. M.; COELHO, I. L.; SOUZA, C. M. N. (org.). Variação estilística: reflexões teórico-metodológicas e propostas de análise. Coleção Linguística. v. 3. Florianópolis: Insular, 2014. p. 141-162.

ECKERT, P. Linguistic variation as social practice. Oxford: Blackwell, 2000.

ECKERT, P. Style and social meaning. In: ECKERT, P.; RICKFORD, J. R. (ed.). Style and sociolinguistic variation. Cambridge: Cambridge University Press, 2001. p. 119-126.

FARACO, C. A. Norma culta brasileira: desatando alguns nós. São Paulo: Parábola Editorial, 2008.

FREITAG, R. M. K. Dissecando a entrevista sociolinguística: estilo, sequência discursiva e tópico. In: GÖRSKI E. M.; COELHO, I. L.; SOUZA, C. M. N. (org.). Variação Estilística: reflexões teórico-metodológicas e propostas de análise. Coleção Linguística. v. 3. Florianópolis: Insular, 2014. p. 123-139.

GÖRSKI, E. M.; VALLE, C. R. A variação estilística em entrevistas sociolinguística: uma (re) leitura do modelo laboviano. In: GÖRSKI E. M.; COELHO, I. L.; SOUZA, C. M. N. (org.). Variação estilística: reflexões teórico-metodológicas e propostas de análise. Coleção Linguística. v. 3. Florianópolis: Insular, 2014. p. 67-92.

HILGERT, J. G. (org.). A linguagem falada culta na cidade de Porto Alegre: materiais para o seu estudo. Passo Fundo: EDIUPF; Porto Alegre: EdUFRGS, 1997.

LABOV, W. The anatomy of style-shifting. In: ECKERT, P.; RICKFORD, J. R. (ed.). Style and sociolinguistic variation. Cambridge: Cambridge University Press, 2001. p. 85-108. 
LABOV, W. Padrões sociolinguísticos. Tradução Marcos Bagno, Maria Marta Pereira Scherre e Caroline Rodrigues Cardoso. São Paulo: Parábola Editorial, 2008.

LíNGUAPOA. Universidade Federal do Rio Grande do Sul. 2015-2019 (período de coleta). Disponível em: https://www.ufrgs.br/linguapoa/. Acesso em: 27 maio 2020.

MARCUSCHI, L. A. Análise da conversação. 5. ed. São Paulo: Editora Ática, 2003.

MILLER, D.; BIBER, D. Evaluating reliability in quantitative vocabulary studies: The influence of corpus design and composition. International Journal of Corpus Linguistics, v. 20, n. 1, p. 30-53, 2015.

OUSHIRO, L. Transcrição de entrevistas sociolinguísticas com o ELAN. In: FREITAG, R. M. K. (org.). Metodologia de coleta e manipulação de dados em sociolinguística. São Paulo: Blücher, 2014. p. 117-131.

PRETI, D. Sociolinguística - os níveis da fala: um estudo sociolinguístico do diálogo na literatura brasileira. 9. ed. São Paulo: EdUSP, 2000.

SCHILLING-ESTES, N. Exploring intertextuality in the sociolinguistic interview. In: FOUGHT, C. (ed.). Sociolinguistic variation: critical reflections. Oxford/New York: Oxford University Press, 2004. p. 44-61.

SCHILLING-ESTES, N. Stylistic variation and the sociolinguistic interview: a reconsideration. In: MONROY, R.; SÁNCHEZ, A. (ed.). Actas del XXV Congreso internacional de la Asociación Española de Linguística Aplicada (AESLA). Murcia, 2007. p. 971-986. Disponível em: https://www.um.es/lacell/aesla/contenido/pdf/9/ schilling.pdf. Acesso em: 2 jul. 2021.

TEIXEIRA, T. T. Níveis estilísticos nas entrevistas do Língua POA: análise conforme a Árvore de Decisão. In: XXXII Semana de Iniciação Científica UFRGS, 2020, Porto Alegre.

VALLE, C. R. N.; GÖRSKI, E. M. Por um tratamento multidimensional da variação estilística na entrevista sociolinguística. In: GÖRSKI E. M.; COELHO, I. L.; SOUZA, C. M. N. (org.). Variação estilística: reflexões teórico-metodológicas e propostas de análise. Coleção Linguística. v. 3. Florianópolis: Insular, 2014. p. 93-121. 
- Alternância de estilo em entrevistas sociolinguísticas: uma aplicação dos critérios da Árvore de Decisão laboviana

WEINREICH, U.; LABOV, W.; HERZOG, I. Fundamentos empíricos para uma teoria da mudança linguística. Tradução Marcos Bagno. São Paulo: Parábola Editorial, 2006.

COMO CITAR ESTE ARTIGO: BATTISTI, Elisa; SANTOS, Bruna Silva dos; GUTTERRES, Rodrigo Lerner; TEIXEIRA, Thomaz Torres; Victória Goulart CUNHA. Alternância de estilo em entrevistas sociolinguísticas: uma aplicação dos critérios da Árvore de Decisão laboviana. Revista do GEL, v. 18, n. 3, p. 311334, 2021. Disponível em: https://revistadogel.gel.org.br/

Submetido em: 21/07/2021 | Aceito em: 14/09/2021. 